\title{
La performatividad de lo masculino en la construcción de una identidad femenina: los retratos de romaine brooks y tamara de lempicka
}

\section{Performing the masculine in the construction of a feminine identity: the portraits of romaine brooks and tamara de lempicka}

Rosa María Bravo Valdés ${ }^{a}$

\begin{abstract}
:
Through portraiture, painters Romaine Brooks and Tamara de Lempicka used fashion to construct a new narrative of the modern woman, one that subverted the heteronormative gender discourse of the early $20^{\text {th }}$ century. Their aesthetic proposals, both of which combined masculine and feminine signs seamlessly, were groundbreaking in representing women in a way that showcased a diversity of sexual and gender expression that was impossible to label. Through an analysis of performativity, and using gender theory, we uncover how both artists used masculinity and androgynous elements towards a creation of a feminine identity.
\end{abstract}

\section{Keywords:}

modernity, performativity, gender identity, portraiture, fashion

\section{Resumen:}

A través del retrato, las artistas plásticas Romaine Brooks y Tamara de Lempicka utilizaron la moda para construir una nueva narrativa de la mujer moderna, que subvertía el discurso heteronormativo de género de principios del siglo XX. Sus propuestas estéticas, en dónde combinaban diestramente signos masculinos y femeninos, fueron parteaguas en mostrar representaciones de la mujer que no la encasillaban, sino al contrario, demostraban una diversidad de expresión sexual y de género que era imposible de categorizar. Mediante un análisis de la performatividad, apoyado en la teoría de género, revelamos cómo las artistas utilizan la masculinidad y los elementos andróginos para la creación de una identidad femenina.

Palabras Clave:

modernidad, performatividad, identidad de género, retrato, moda.

\section{INTRODUCCIÓN}

"La Modernidad es esa teatralidad que constantemente erotiza lo nuevo"*

- Christine Buci-Glucksmann
Es en el rostro ajeno que empezamos a definirnos a nosotros mismos, al reconocernos o diferenciarnos. La noción de identidad moderna nos empuja a ser cada vez más introspectivos y conscientes de cómo somos y cómo nos desenvolvemos en el mundo. Implica una cuidadosa construcción del Ser que busca encontrarse, reflejado y representado, en el Otro. Oscilamos siempre entre la identidad individual y la colectiva, a través de una serie de

\footnotetext{
* Esta cita y todas las demás que se incluyen en el texto fueron traducidas al español por la autora.

a Autor de Correspondencia, Instituto Nacional de Bellas Artes y Literatura, https://orcid.org/0000-0001-9283-9812, Email: larosa33@hotmail.com
} 
herramientas, indudablemente modernas, que nos permiten construirnos. La moda, por ejemplo, se ha vuelto indispensable como la manera en la que nos construimos, a través de la estética, el artificio y la apariencia, para identificarnos dentro del colectivo.

En este artículo analizaremos los elementos de la masculinidad en la creación de la identidad femenina moderna dentro del contexto social y cultural del siglo XX, mediante el uso de investigación bibliográfica y el análisis de los elementos visuales de dos obras pictóricas como ejemplos y puntos de partida. El desarrollo de la industria de la moda, a la par de las vanguardias artísticas, es precisamente lo que vuelve al siglo XX la cuna de la identidad moderna. Dos artistas que ejemplifican no sólo el uso de la moda, sino también del arte para definir nuevas posibilidades de Ser, fueron Romaine Brooks y Tamara de Lempicka, quienes a través del retrato no sólo definen lo que significa ser una mujer moderna, sino logran crear una nueva narrativa de género andrógino imposible de categorizar.

Si al siglo XIX le concierne la industrialización y urbanización que cementan lo que será la era moderna, el siglo XX trata de definir la modernidad en todas sus capacidades, incluida la construcción de identidades cada vez más plurales, diversas, e introspectivas. En las primeras décadas del siglo, y en particular el periodo entreguerras en Europa, se aprecia una creciente preocupación por definir los matices de la modernidad. Una progresiva clase bohemia de artistas e intelectuales redefinen lo que significa Ser, a través de las artes y la literatura, pero principalmente a través de sí mismos. La industrialización del siglo pasado había permitido una creciente democratización de servicios y bienes; lo que antes pertenecía a las élites cada vez se volvía más accesible para todos. Fue la moda, sobre todo, lo que cobró particular importancia. A partir de la Belle Époque, la gente empieza a vestirse para ser vista en el plano público, y la vestimenta vuelve al cuerpo un sitio de signos y símbolos discursivos.
La brutalidad de la primera guerra mundial, seguida por la influenza española, significó una escasez de hombres en Europa. Esto, aunado a la creciente independencia que habían ganado las mujeres de posguerra, significó que cada vez más eran precisamente ellas quienes tomaban el primer plano y se permitían crear, para sí mismas, nuevas narrativas de identidad de género de la mujer moderna. Fue en este contexto que surgió Gabrielle "Coco" Chanel, iconoclasta que rechazó totalmente la estética de la moda de principios del siglo al adaptar elementos del vestir masculino y de ropa de trabajo a una nueva silueta femenina, funcional y dinámica. La popularidad e impacto que tiene el nuevo uniforme de Chanel recuerdan al arquetipo del dandy original, Beau Brummell.

El dandismo se introdujo en el imaginario colectivo con Brummell en la Inglaterra del período Regencia, un siglo antes. A él se le atribuye la creación del uniforme moderno de la moda masculina, así como la idea del vestir y el estilo como medio de encarnar una identidad social única.

Durante el resto del siglo, se iría reconstruyendo la pauta estética de Brummell en lo que eventualmente se convierte en el traje de tres piezas hacia finales de siglo, al tiempo que se establecen las normas de la masculinidad moderna. El traje se vuelve un símbolo de la masculinidad heteronormativa y es, por sí mismo, un signo de autoridad y rango social. Para Susan Sontag, el dandismo representaba un proyecto estético que busca ver al mundo como un fenómeno estético, artificial, estilizado: el dandy es puro estilo, artificio despojado de sustancia.

Sin embargo, el dandy no sólo se construye a través de cuestiones frívolas, ni se caracteriza únicamente por un vestuario elegante y exagerado, sino también por un despliegue de gesto, intelecto e ingenio, tanto verbal como encarnado, un performance a través de la repetición de actos corporales estilizados (Butler, 2007). Baudelaire y los poetas malditos de la Belle Époque resignifican al dandy, dándole sustancia intelectual y volviéndolo un símbolo de discordia contra las normas heterosexuales y materialistas 
de la burguesía. El dandy ahora se presentaba como figura política y disidente en contra del orden hegemónico, o en palabras de Barbey d'Aurevilly, "la revuelta del individuo en contra del orden establecido". El dandy se convierte así en una figura que emerge como respuesta crítica a circunstancias cambiantes, en tiempos de cambio cultural, social y político. Es una figura semiótica: interpreta y es interpretado, es crítica de las normas en declive y potencia de identidades emergentes. El dandismo, entonces, existe más allá de cuestiones normativas de género y sexualidad. La dialéctica dandista existe entre lo masculino y lo femenino, heterosexual y homosexual. Es un performance estético de masculinidad, una deconstrucción y reconstrucción de identidad independiente de la raza, clase social, o género.

\section{DESARROLLO}

Hacia los años veinte en Paris, surgió un colectivo lésbico de intelectuales bohemias, entre ellas Romaine Brooks y Radclyffe Hall, que acostumbraba a subvertir las convenciones de género de la época a través del travestismo. A pesar de que las tendencias de la época favorecían a mujeres adoptando estilos masculinos, para este grupo, adoptar el traje de tres piezas, el pelo corto y el monóculo significaba su independencia tanto como su disponibilidad sexual. Cabe recordar que, durante este periodo, nociones de homosexualidad, lesbianismo y lo "femenino" seguían estando atadas a la perversidad decadente de fines de siglo XIX (Glick, 2009). La identidad modernista se estaba intentando definir como el total opuesto: normal, ordenada, heterosexual, de carácter totalmente "masculino", al tiempo que surge la dandy lésbica, que reclama el arquetipo para alejarse de la femineidad Sáfica decadente de finales de siglo. Al adoptar elementos estéticos de Brummell, sumándolos al carácter intelectual, bohemio y maldito de Baudelaire, intentaba romper con el esquema binario de género al introducir una nueva narrativa andrógina de expresión sexual, abriendo las puertas, por lo tanto, a un potencial de posibilidades de identidad no binaria.

Hay que recordar, también, que los discursos médicos y psicoanalíticos de la época situaban a la lesbiana como una suerte de tercer sexo, gracias a las teorías de "sexo invertido". Es por eso que, en la construcción de Brooks y su círculo social, la lesbiana se imagina como andrógina, combinando diestramente elementos masculinos y femeninos. Radclyffe Hall, en su obra El pozo de la soledad (1928) propone la identidad lésbica masculina como una repudiación de lo decadente y la femineidad; sin embargo, al tratar de modelar a la lesbiana varonil como la apoteosis del recato burgués, Hall se apoya en la figuración del esteta ocioso y dandificado. Al basar su trabajo en las nuevas definiciones médicas de la homosexualidad, logra articular un concepto de dandismo queer que manifiesta sus esenciales contradicciones de una nueva manera. El cambio en la percepción pública de la lesbiana, que había pasado de la perversidad a la inversión, del pecado al desorden médico, empujó a Hall a localizar la esencia de la sexualidad lésbica dentro de un cuerpo que se percibía anormal y desviado, a pesar de ser también natural. (Glick, 2009).

La filósofa Judith Butler, en su monumental obra El género en disputa, construye sobre la noción de Simone de Beauvoir de que no se nace mujer, sino se llega a serlo. Pone al sexo como un término que está en proceso, en construcción, sin principio ni fin. El género es entonces una práctica discursiva, abierta a intervención y resignificación: "la categoría de 'sexo' es un nombre que esclaviza."

Argumenta que la subversión sólo puede ocurrir a través de la repetición de actos paródicos (Butler, 2007). Lo femenino, como lo repudiado dentro del sistema, constituye por sí mismo la posibilidad de una crítica o disrupción al esquema hegemónico conceptual. La dandy lésbica, entonces, se convierte en disrupción en dos partes: la Otredad de ser mujer, y la parodia de adoptar el traje. Si el dandy de Brummell representó en su momento la movilidad 
social, el dandy lésbico representa la movilidad sexual, o quizás en términos contemporáneos la fluidez sexual y de género.

Es precisamente en el periodo entreguerras que hay una explosión de propuestas de mujeres artistas, escritoras e intelectuales que ejemplifican la diversidad de expresiones que podía significar la mujer moderna. La fotografía Surrealista y radical de Claude Cahun, los retratos andróginos de Hannah Gluck, la influencia de Gertrude Stein o los icónicos momentos en pantalla de Marlene Dietrich son sólo algunos ejemplos del alcance que estaban teniendo en todos los ámbitos artísticos y sociales. El impacto duradero de algunas de estas obras, aclamadas y repudiadas aún hoy día, es evidencia de la importancia que la representación artística tiene en el imaginario colectivo. Entre las obras más representativas y controversiales de la década se encuentra Orlando: una biografía (1928) de Virginia Woolf, en donde escribe, "por diversos que sean los sexos, se confunden. No hay ser humano que no oscile de un sexo al otro, y a menudo sólo los trajes siguen siendo hombres o mujeres, mientras que el sexo oculto es lo contrario a lo que está en vista.” (Woolf, 2018). La escritora inglesa pone en términos simples lo que se vislumbra en la totalidad de las obras de las creadoras de la época, el "sexo oculto" que resultaba andrógino, la identidad de género como intercambiable y pasajera. Es imposible llegar a una conclusión o término de lo que significaban estos nuevos paradigmas pues estaban llenos de contradicciones; eran, al igual que sus creadoras, de carácter ambiguo.

Peggy Phelan argumenta que la identidad es discernible solo en relación con un otro, declarando la demarcación donde el yo se separa y se fusiona con el otro. En esa declaración de identidad siempre hay pérdida, la pérdida de no ser el otro, y seguir necesitando a ese otro para completarse. Dos artistas que evidencian esto a través de la pintura son Romaine Brooks y Tamara de Lempicka. La extensa obra pictórica de ambas muestra una afinidad por el retrato y la realización de una estética que era tanto explícitamente distinta al de sus contemporáneos como ferozmente personal. Diametralmente opuestas en términos de estilo, uso de color y forma, son ejemplares de la manera en que la representación y reproducción del Otro produce la identidad propia, así como puede llegar a visibilizar y normalizar cuerpos y conductas de otra forma marginalizados. Si la representación reproduce al Otro como Igual (Phelan, 1993), el legado de estas dos pintoras es autobiografía pura. El retratar se vuelve para ellas una relación simbiótica: se plasman ellas mismas en el retrato ajeno, y construyen su propia identidad a través del mismo. En términos propios de Butler, se puede leer lo real a través de la representación, y la representación a través de lo real. (Lucchesi, 1998).

Tanto Tamara de Lempicka como Romaine Brooks poseían una base sólida de dibujo académico, y ambas combinan elementos de realismo con estilización decorativa. Las raíces del estilo de Brooks se encuentran en la Belle Époque y el estilo Art Nouveau, en tanto que de Lempicka se basa más en la era Moderna del Jazz y el Art Déco.

Quizás la comparación más común entre ambas artistas sea la del retrato de La Duquesa de la Salle creado por de Lempicka en 1925 (figura 1) y el retrato de Brooks de Una, Lady Troubridge en 1924 (figura 2). Coinciden en que ambas modelos fueron íconos del lesbianismo parisino y fueron pintados con un año de diferencia (Bade, 2006). Los dos retratos muestran a mujeres vestidas en atuendos masculinos, sin dejar ver el menor indicio de curvas femeninas. La masculinidad de la Duquesa se muestra en su fornido cuerpo y sus pesadas botas de montar, mientras que la delgada Lady Troubridge se muestra empoderada, acompañada de dos perros salchicha de carácter totalmente fálico y vestida al estilo más fiel de la moda lésbica. Ambas miran de frente al espectador, decididas y desafiantes. 
Romaine Brooks se caracteriza por ser una de las primeras artistas que crea desde y para la mirada femenina; se le ha reconocido como una Safo moderna, celebrando la fluidez de género y creando arte queer con imágenes de personas fuertes, tanto mujeres como no binarias (Chadwick, 2000). Para ella, el retrato constituía una acción radical y desafiante: era moderna en su deconstrucción del retrato de sus cánones tradicionales. Sus retratos son un juego de la mirada, de voyeurismo, de ver y ser visto que vuelven al retrato un espejo que cuestiona al sujeto y al espectador. La mujer de Brooks es una heroína queer moderna, que utilizaba la moda como metáfora de ambigüedad sexual, y logra romper con suposiciones heteronormativas de género (Langer, 2010). En su Autorretrato de 1923, (figura 3), se muestra también en atuendo masculino, pero a diferencia de Lady Troubridge, no es el disfraz dandy de la era, sino algo más casual y relajado, sin dejar de ser, por supuesto, un atuendo elegante y al más fiel estilo de la moda de la

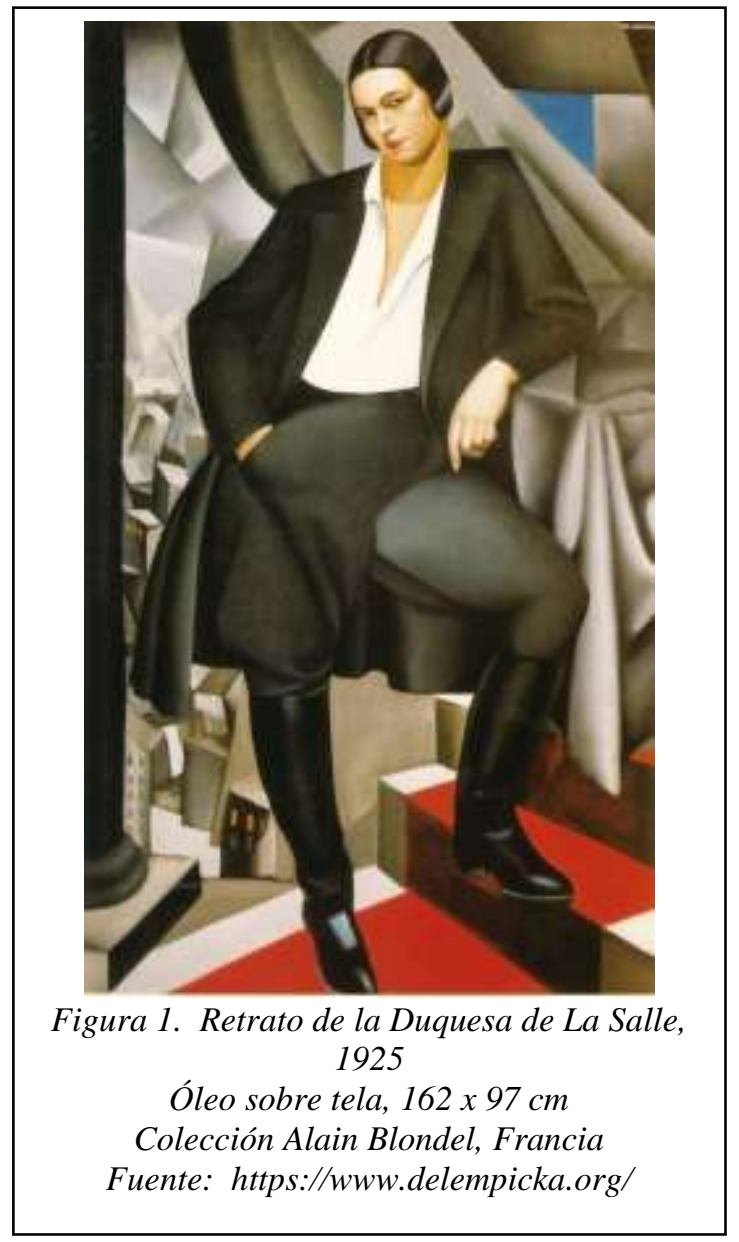

época. Brooks se muestra a sí misma en la cotidianeidad, igualmente enfrentando al espectador, aunque esta vez de manera más sutil, con la ciudad insinuada al fondo. Con el rostro velado por la sombra del sombrero de copa, se difumina aún más la línea entre lo masculino y lo femenino. Si Lady Troubridge muestra a la lesbiana como punto de exclamación, Romaine Brooks la plasma, en su propia imagen, como punto de interrogación.

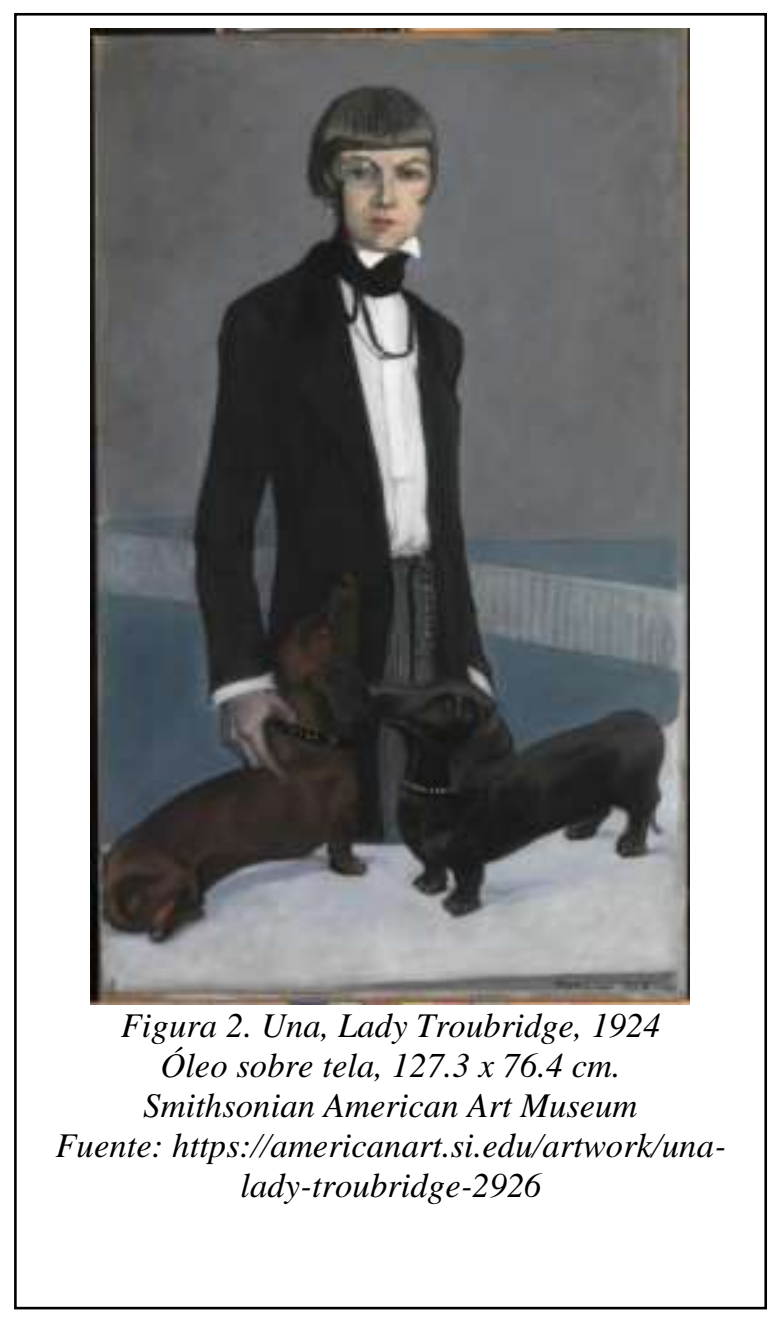


El retrato constituía, para Tamara de Lempicka, una oportunidad de construirse a sí misma, aún a través de otras personas. Ella misma afirmó que todas sus pinturas eran autorretrato, (figura 4) y que la fascinación por la práctica constituía en ella una "obsesión masculina” (Claridge, 2001). La estrategia de mezclar elementos clásicos y académicos con la vanguardia y las obsesiones modernistas de la época ayudaron a popularizar el trabajo de la artista hacia la segunda mitad de los años veinte. Los críticos percibían su obra como indudablemente moderna en su síntesis de contradicciones, no sólo de técnica sino también la yuxtaposición de sensualidad y frialdad que emanan sus sujetos (Bade, 2006). De Lempicka creaba a partir de esta técnica una ambigüedad de identidad, sin duda de carácter sexual. La mujer a través de sus retratos era autosuficiente, sensual, elegante, segura de sí misma, intensamente moderna. En La Duquesa de la Salle, es cuidadosa en como construye una masculinidad femenina a través de las proporciones del cuerpo, el gesto, el poder dominante que

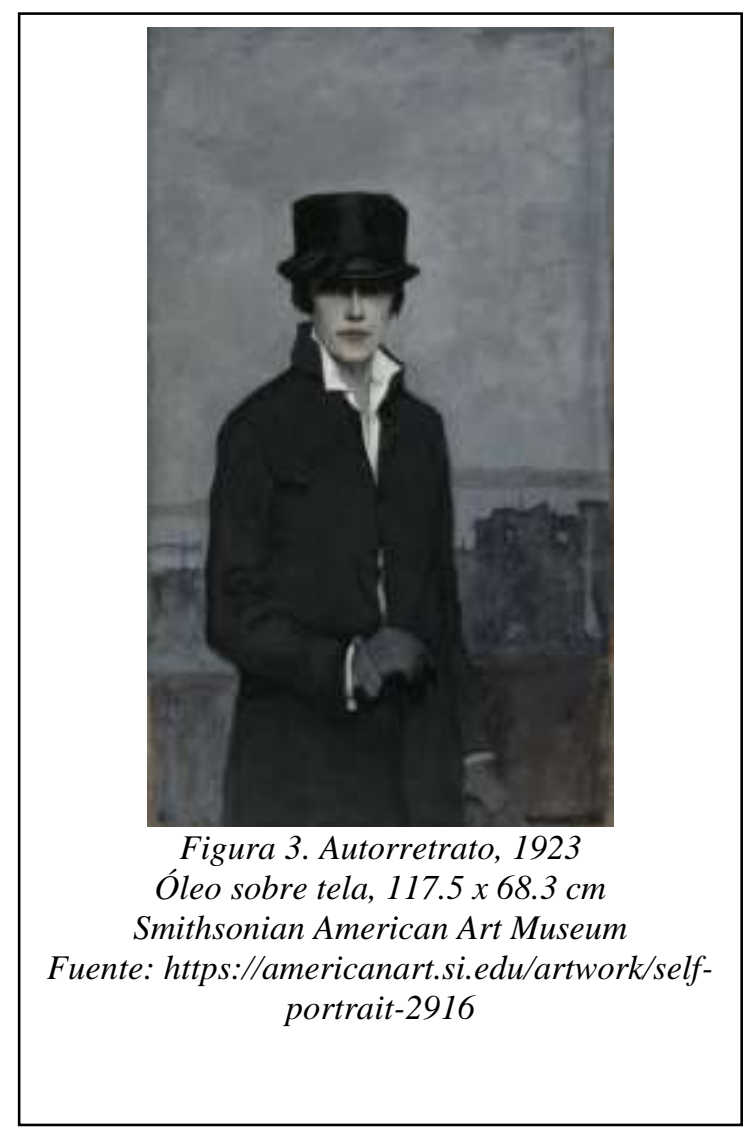

emana el traje y las botas que vuelven a la duquesa el modelo de la mujer amazona. La obra se perfila al puro estilo de un retrato aristocrático del siglo XVII, pero la atención al detalle, la ciudad cubista de fondo, y la moda de la duquesa lo vuelven decididamente moderno. Una fotografía publicitaria de la recámara de De Lempicka, que mostraba este cuadro arriba de la cama, funcionó como un guiño a la bisexualidad y libertad sexual propias de la pintora.

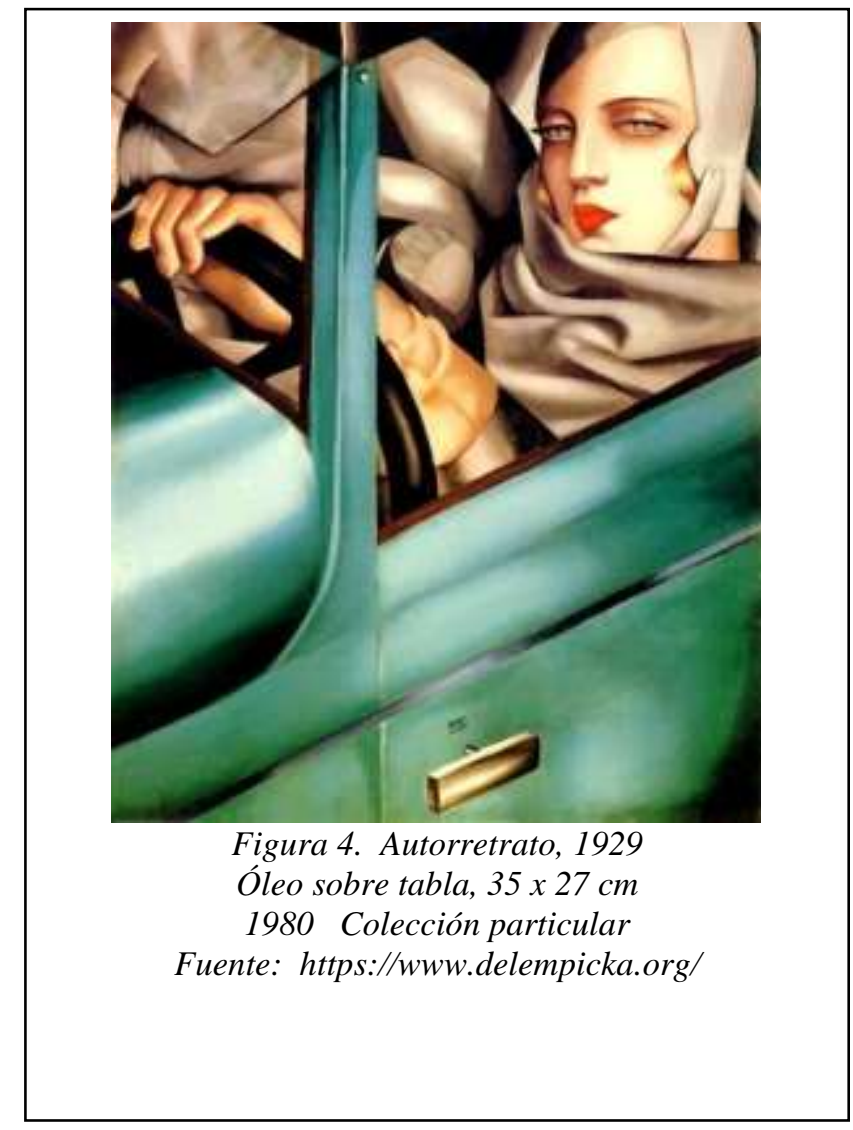

Ambas artistas lograron una nueva metáfora pictórica de la mujer del siglo XX que no encajaba con anteriores categorizaciones de la femineidad. De Lempicka plasmaba un hedonismo libre de culpas en sus mujeres, a quienes retrató en su mayoría como objetos sexuales pasivos, rodeadas de signos de la modernidad (Bade, 2006). Sus retratos, y en particular sus autorretratos, eran proyecciones del mundo que ella deseaba, y del personaje público que se había creado tan meticulosamente. Su femineidad era a la vez seductiva y fría. Donde la mujer que imagina De Lempicka es amazona, autosuficiente, apropiándose de características masculinas, la mujer de Brooks es mártir, heroína trágica que se construye a partir de contradicciones 
y ambigüedades. La artista no tenía mucho que ver con el arquetipo de amazona, y lo que su estética queer hace es utilizar las dinámicas introspectivas del retrato para construir a la lesbiana moderna que enfatiza la ambigüedad de las normas binarias de género. Sus imágenes le permitieron usar al cuerpo como signo, señalando la opresión patriarcal y un nuevo empoderamiento femenino (Lucchesi, 1998). En donde coinciden ambas artistas es en la repetición del retrato para reiterar sus discursos de mujer moderna. Al desprenderse de la mirada masculina, no sólo cementaban su estilo pictórico, que en ambos casos es totalmente distinto al de sus contemporáneos, pero también se construían a ellas mismas y normalizaban estos nuevos roles de la mujer, abriendo un espacio andrógino que validaba sus experiencias de mujeres no normativas.

Los retratos de mujeres masculinizadas estaban de moda en este periodo; recordemos que, después de todo, eran los años en que Chanel dictaba las pautas del estilo, y las flappers o garçonnes dominaban los clubes de jazz. Pero a pesar de lo relativamente común que resultan la moda y el retrato andrógino, estos no dejan de ser provocativos, y ciertamente revolucionarios. Lo que logra la obra de Brooks y de Lempicka es subvertir aún a través de lo cotidiano, y ambas artistas demuestran maestría al utilizar precisamente lo ordinario — la moda - para llevar al plano público su discurso de género: ambas reiteran la vestimenta como un signo performativo y discursivo. En sus obras, el retrato funciona como una descontextualización de un objeto cotidiano, trasladado a un lugar insólito y socialmente inaceptable para resaltar su condición de signo (Calefato, 2004). La pintura fue, para ellas, una extensión de la performatividad de género al usarla como una herramienta para definirse y proyectarse al mundo. Al construir el retrato como se construían ellas mismas, no sólo rompieron paradigmas sexuales sino también estéticos gracias a sus muy distintos, pero igualmente distintivos usos del color, la forma, el gesto y corporeidad de sus modelos. La repetición de temas a lo largo de sus obras logró visibilizar cuerpos que, de otra forma, existirían únicamente en los márgenes de la historia.

\section{CONCLUSIÓN}

El revisitar estas propuestas dentro del contexto actual, y en el marco de las teorías de género contemporáneas, ciertamente enfatiza lo progresivas que fueron estas dos artistas y el impacto que causaron las representaciones estéticas e intelectuales de principios del siglo XX en los discursos de género actuales. Sus retratos, que no necesariamente buscaban provocar, aunque tal vez sí incomodar, lograron introducir perspectivas nuevas de género y expresión sexual que continúan vigentes en el imaginario colectivo. Buscaban representar mujeres que no estaban enmascaradas, sino se mostraban en su cotidianeidad queer, sin exigir más que visibilidad y validación. Cabe reiterar la condición simbiótica que forman ambas con la pintura, y la fijación que tuvieron de retratar a otros a lo largo de sus carreras artísticas, lo cual demuestra una necesidad del Otro para completarse. Más que práctica, el retrato era una extensión de su identidad, y funcionaba como herramienta performativa para definirse en el mundo. Si lo que buscaban tanto Tamara de Lempicka como Romaine Brooks era definirse ellas mismas, encontrarse en sus modelos, o si la fijación de representar y reproducir estos cuerpos funcionaba a manera de escape de la soledad propia de la Otredad, el retrato quizás significaba, para ellas, un espacio de comunión, y una posibilidad de crear un diálogo con el espectador para reconocerse el uno al otro. 


\section{REFERENCIAS}

- Bade, P. (2006). Tamara de Lempicka. New York: Parkstone Press International.

- Blondel, A. and De Lempicka, T. (1999). Tamara De Lempicka Catalogue Raisonné 1921-1979. Lausanne : Acatos.

- Buci Glucksmann, C. (1994). Baroque Reason: The Aesthetics of Modernity. London: Sage.

- Butler, J. (2007). El género en disputa: El feminismo y la subversión de la identidad. México: Paidós.

- Bravo, V. R. (2013). Tamara De Lempicka: Sus retratos y su influencia en la moda de los años 20. Tesis de maestría no publicada, Universidad Centro de Arte Mexicano, México.

- Calefato, P. (2004). The clothed body. New York: Berg.

- Chadwick, W. y Lucchesi, J. (2000). Amazons in the Drawing Room: The Art of Romaine Brooks. Chesterfield, Mass: Chameleon Books.

- Claridge, L. (2001). Tamara de Lempicka. Barcelona: Circe.

- Evans, C. (2003). Fashion at the edge: spectacle, modernity and deathliness. USA Yale University Press.

- Glick, E. (2009). Materializing Queer Desire: Oscar Wilde to Andy Warhol. New York: State University of New York Press.

- Langer, C. (2001). Woman's Art Journal, 22(2), 44-47. doi:10.2307/1358903

- Langer, C. (2010). Reframing Romaine Brooks' Heroic Queer Modernism, Journal of Lesbian Studies, 14:2-3, 140-153, DOI: $10.1080 / 10894160903196525$
- Lucchesi, J. (1998) Romaine Brooks' SelfPortrait Photographs and the Performance of Lesbian Identity, nombre de la revista (vol. 16 (1998) versión electrónica en https://journals.flvc.org/athanor/article/view/1 26435, consultado 29 de enero de 2021

- Phelan, P. (1993). Unmarked: The Politics of Performance. New York: Routledge

- Seeling, Ch. (2000). Moda. El siglo de los Diseñadores 1900-1999. España: Köneman.

— Woolf, V. (2018). Orlando. Una biografía. Argentina: Akal. 